\title{
Interest of the Androgen Deficiency in Aging Males (ADAM) questionnaire for the identification of hypogonadism in elderly community-dwelling male volunteers
}

\author{
Annalisa Tancredi ${ }^{1,2}$, Jean-Yves Reginster ${ }^{1,2,3}$, Florence Schleich ${ }^{4}$, Georges Pire ${ }^{6}$, Philippe Maassen ${ }^{7}$, \\ Françoise Luyckx ${ }^{5}$ and Jean-Jacques Legros ${ }^{4}$ \\ ${ }^{1}$ WHO Collaborating Center for Public Health Aspect of Osteoarticular Disorders, Liège, Belgium, ${ }^{2}$ Department of Public Health and Epidemiology, ${ }^{3}$ Bone \\ and Cartilage Research Unit, ${ }^{4}$ Department of Endocrinology, Psychoneuroendocrinology Unit, and ${ }^{5}$ Department of Clinical Chemistry, University of Liège, \\ Belgium, ${ }^{6}$ Representative in charge of Health, Environment and Quality of Life, Province of Liège, Belgium and ${ }^{7}$ General Director, Health and Environment, \\ Province of Liège, Belgium
}

(Correspondence should be addressed to Annalisa Tancredi, Department of Public Health Sciences, Epidemiology and Health Economics, University of Liège, CHU Sart Tilman, Avenue de l'Hôpital, Bâtiment B23, 4000 Liège, Belgium; Email: annalisa.tancredi@ulg.ac.be)

\begin{abstract}
Objective: To date, serum free testosterone measurement is considered to be the gold standard for the diagnosis of hypogonadism in elderly males but it is not available to all subjects suspected of a decrease in testicular function. Therefore, we evaluated whether the Androgen Deficiency in Aging Males (ADAM) questionnaire, in its original or in a modified 'quantitative' version (qADAM), could be used as a surrogate to biochemical determinations for the identification of hypogonadism in elderly males.

Methods: 5028 men, aged 50-70 years, spontaneously consulting for the assessment of their gonadal function were studied. ADAM and qADAM, allocating a value of 1 point for any positive answer to each of the 10 questions of the ADAM test, were assessed for their ability to discriminate between males with free testosterone levels below or above $70 \mathrm{ng} / \mathrm{l}$.

Results: The sensitivity and specificity of the ADAM score were $81 \%$ and $21.6 \%$ respectively. The use of ADAM resulted in an appropriate classification of our population in normal or hypogonadal subjects in $44.5 \%$ of the cases. The area under the receiver operating characteristics (ROC) curve for the qADAM (0.529) revealed a highly marginal interest of this quantitative approach compared with the original scoring system.

Conclusions: The ADAM test has a high sensitivity to identify aging males with low free testosterone levels. However, due to its lack of specificity, this test cannot be used as a surrogate to serum free testosterone testing for the identification of androgen deficiency in elderly, community-dwelling males.
\end{abstract}

European Journal of Endocrinology 151 355-360

\section{Introduction}

During the last century, life expectancy has risen sharply in most developed countries, drawing attention to physiological or pathological conditions that specifically affect elderly individuals $(1,2)$.

In both genders, gonadal function decreases with age (3). Women at the time of the menopause present a sudden discontinuation of ovarian activity, resulting in a drastic decrease of circulating estrogen levels and a rapid onset of subsequent climacteric symptoms. In aging men, a more progressive decrease in testosterone production is observed and has been linked in some individuals to a complex clinical syndrome, including physical and psychological alterations, which by analogy with the female menopause has been called andropause $(4,5)$. Whether andropause is a disorder or a normal manifestation of aging remains controversial
$(5,6)$. However, since the development and the commercial availability of chemical entities able to compensate for testosterone deficiency and that have been shown to improve the quality of life of these aging males $(7-14)$, much effort has been dedicated to identify male subjects who should benefit from such hormonal replacement therapy $(15-20)$. So far, the gold standard for the diagnosis of primary or secondary hypogonadism is the serum measurement of free testosterone (4). However, as with any laboratory measurement, this requires collection of body fluid and, due to economic and technical constraints, it is not available to any single individual suspected of a decrease in testicular function.

Attempts were made to develop simple, user-friendly, non-invasive tools that would identify andropausal men on the basis of their clinical presentation (21-25). While preliminary results obtained with some of these 
tools are promising, their surrogacy to the biochemical measurement of circulating androgen levels has not been unequivocally demonstrated.

The objective of our study was to evaluate whether a simple, self-administered questionnaire, the Androgen Deficiency in Aging Males (ADAM) score (23) could be used as a surrogate to serum free testosterone testing for the identification of androgen deficiency in elderly community-dwelling males. We also designed a modified 'quantitative' version of the score and compared its diagnostic value with the results obtained with the original tool.

\section{Material and methods}

As part of the European Health Education program of the World Health Organisation, all men aged 50-70 years and living in the Liège area $(n=12796)$ were invited by the Health Authority of the Province of Liège to attend a free screening campaign aimed at the detection of prostatic cancer and andropause.

A venous fasting blood sample was drawn between 0900 and $1130 \mathrm{~h}$ for the assessment of total testosterone, sex hormone binding globulin (SHBG), follicle-stimulating hormone (FSH) and luteinizing hormone (LH). The samples were immediately centrifuged and frozen at $-70^{\circ} \mathrm{C}$. All determinations were performed using commercially available electrochemiluminescence immunoassays (ECLIA). Total testosterone, SHBG, LH and FSH were measured using the Elecsys Systems 2010 (Roche, Basel, Switzerland). For total testosterone, the intra- and interassay coefficients of variation $(\mathrm{CV})$ varied from 0.9 to $4.6 \%$ and from 1.6 to $7.4 \%$ respectively. For SHBG, the intra- and interassay CV varied from 2.1 to $2.7 \%$ and from 2.6 to $5.6 \%$ respectively. For $\mathrm{LH}$, the intra- and interassay $\mathrm{CV}$ varied from 0.8 to $1.8 \%$ and from 1.9 to $5.2 \%$ respectively. For FSH, the intra- and interassay CV varied from 1.4 to $2.0 \%$ and from 2.9 to $5.3 \%$ respectively.

Free testosterone (FT) was indirectly obtained by the calculation of the formula developed and validated by Vermeulen et al. 1999 (26):

$$
[\mathrm{FT}]=\frac{[\mathrm{T}]-\mathrm{N}^{*}[\mathrm{FT}]}{K_{\mathrm{SHBG}} *\left\{[\mathrm{SHBG}]-[\mathrm{T}]+\mathrm{N}^{*}[\mathrm{FT}]\right\}}
$$

where $\mathrm{N}=1+K_{\mathrm{A}} *[\mathrm{~A}],[\mathrm{T}]=$ total serum testosterone concentration in $\mathrm{mol} / \mathrm{l}$, [SHBG] $=$ sex hormone binding globulin serum concentration in $\mathrm{mol} / \mathrm{l}$, [A] = serum albumin concentration in $\mathrm{mol} / \mathrm{l}, K_{\mathrm{SHBG}}=$ affinity constant of testosterone for $\mathrm{SHBG}=1 \times 10^{9} \mathrm{~mol} / \mathrm{l}$, $K_{\mathrm{A}}=$ affinity constant of testosterone for albumin $=3.6 \times 10^{4} \mathrm{~mol} / \mathrm{l}$.

Based on the previous study (27), andropause was considered to be present when free testosterone was $<70 \mathrm{ng} / \mathrm{l}$. This free testosterone threshold is similar to the mean value -2 standard deviations (S.D.) $(74 \mathrm{ng} / \mathrm{l})$ obtained in healthy young males 20-40 years of age (28). There is no generally accepted cut off value of free testosterone for defining androgen deficiency, but it is commonly accepted that 2 S.D. below normal values for healthy young men is abnormal $(5,28)$.

Participants were then asked to answer the previously described (27) French version of the Androgen Deficiency in Aging Males (ADAM) questionnaire (23). The ADAM questionaire consists of ten items describing the most common symptoms observed in androgen deficiency and is divided into three dimensions i.e. energy, mood and sexual disorders. The original developer of ADAM considered the test to be positive $(\mathrm{A}+)$ if the subject gives a positive answer to any of the questions pertaining to sexual disorders or to at least three of the other questions. The test is considered to be negative $(\mathrm{A}-)$ in all other cases (Table 1) (23).

We assessed the sensitivity (i.e. the probability that a patient with free testosterone $<70 \mathrm{ng} / \mathrm{l}$ has a positive ADAM test), the specificity (i.e. the probability that a patient with free testosterone $\geq 70 \mathrm{ng} / \mathrm{l}$ has a negative ADAM test), the positive predictive value (PPV) (i.e. the probability that a patient with a positive ADAM test has a free testosterone $<70 \mathrm{ng} / \mathrm{l}$ ) and the negative predictive value (NPV) (i.e. the probability that a patient with a negative ADAM test has a free testosterone $\geq 70 \mathrm{ng} / \mathrm{l}$ ) of ADAM in the perspective of the identification of men with andropause. The global efficiency of ADAM was defined by the percentage of subjects who are correctly classified as either hypogonadic or normal.

We also designed a modified 'quantitative' assessment of the ADAM questionaire (qADAM) in which we allocated the value of 1 to a positive answer to any of the questions, allowing the calculation of a global qADAM score, summing all values, and ranging from 0 to 10 . We assessed the interest of the qADAM score for separating individuals with free testosterone $<70 \mathrm{ng} / \mathrm{l}$ from those with free testosterone $\geq 70 \mathrm{ng} / \mathrm{l}$, by means of Chi-square and unpaired Student's t-test (STATISTICA 5.0, Statsoft, Maisons-Alfort, France). The receiver operator characteristics (ROC) curve of the qADAM for free testosterone $<70 \mathrm{ng} / \mathrm{l}$ was calculated. The area under the ROC curve provides a measure of the ADAM's discriminating power. An area of 1 suggests perfect separation between normal and hypogonadal men, while an area of 0.5 indicates a nondiscriminating test. A two-tailed level of 5\% was considered statistically significant.

\section{Results}

From September 2000 to January 2003, 127796 elderly men were invited to perform the screening tests for prostatic cancer and andropause; $18.7 \%$ of them spontaneously attended the screening for prostatic cancer, whereas for andropause, the response 
Table 1 The Androgen Deficiency in Aging Males (ADAM) questionnaire.

\begin{tabular}{|c|c|}
\hline Original version* & French translation ${ }^{* *}$ \\
\hline $\begin{array}{l}\text { 1. Do you have a decrease } \\
\text { in libido (sex drive)? }\end{array}$ & 1. Avez-vous constaté une diminution de votre libido (désir d'avoir des rapports sexuels)? \\
\hline $\begin{array}{l}\text { 2. Do you have a lack } \\
\text { of energy? }\end{array}$ & 2. Sentez-vous un manque d'énergie? \\
\hline $\begin{array}{l}\text { 3. Do you have a decrease } \\
\text { in strength and/or endurance? }\end{array}$ & 3. Sentez-vous une diminution de force musculaire et d'endurance à l'effort? \\
\hline 4. Have you lost height? & 4. Avez-vous remarqué que vous avez rapetissé? \\
\hline $\begin{array}{l}\text { 5. Have you noticed a decreased } \\
\text { 'enjoyment of life'? }\end{array}$ & 5. Avez-vous remarqué une diminution de votre joie de vivre? \\
\hline 6. Are you sad and/or grumpy? & 6. Vous sentez vous triste et/ou grincheux? \\
\hline 7. Are your erections less strong? & 7. Vos érections sont-elles moins fortes? \\
\hline $\begin{array}{l}\text { 8. Have you noted a recent } \\
\text { deterioration in your ability to } \\
\text { play sport? }\end{array}$ & 8. Avez-vous remarqué une diminution de votre capacité à 'faire du sport'? \\
\hline $\begin{array}{l}\text { 9. Are you falling asleep after } \\
\text { dinner? }\end{array}$ & 9. Tombez-vous endormi après les repas? \\
\hline $\begin{array}{l}\text { 10. Has there been a recent } \\
\text { deterioration in your work performance? }\end{array}$ & 10. Avez-vous remarqué une diminution récente de votre capacité de travail? \\
\hline
\end{tabular}

Affirmative answers to questions 1 or 7 , or to any three other questions provide a positive result on the ADAM questionnaire. * Morley et al. (23); **Legros \& Delhez (27).

rate was $3.9 \%(n=5028)$. The mean age (s.D.) of our sample was 60.0 (5.8) years. The prevalence of hypogonadism (free testosterone $<70 \mathrm{ng} / \mathrm{l}$ ) was $38.6 \%$ $(n=1939)$. A positive ADAM score $(\mathrm{A}+)$ was reported in 3993 men $(79.4 \%)$. The $\mathrm{A}+$ patients were significantly older $(60.4(5.3)$ years $)$ than the A - patients $(58.4(5.6)$ years $)(P<0.001)$. Table 2 shows the serum hormones levels in the two groups $(\mathrm{A}+/ \mathrm{A}-)$. FSH was the only parameter which significantly differed between the two groups $(P<0.04)$.

Table 3 summarizes the percentage of positive answers for all questions of the ADAM score, in the whole sample and in men with free testosterone below or above $70 \mathrm{ng} / \mathrm{l}$. A higher proportion of $\mathrm{A}+$ (following the definition of the developer) was observed in the group of men with free testosterone $<70 \mathrm{ng} / \mathrm{l}$ $(81.0 \%$ vs $78.4 \%, P=0.03)$. A statistically significant difference between men with free testosterone $<$ or $\geq 70 \mathrm{ng} / \mathrm{l}$ was observed for items 1 (libido), 4 (loss of height), 7 (erectile function) and 10 (work performance). When assessing the determinants of the statistical difference in ADAM between men with low and normal free testosterone, we noticed that these results are driven by the rates of positive answers to the questions pertaining to sexual disorders. No significant

Table 2 Hormonal values in individuals with positive $(A+)$ or negative $(\mathrm{A}-$ ) ADAM scores (mean (SD)).

\begin{tabular}{lcrrr}
\hline Hormones & $\begin{array}{c}\text { Total } \\
(n=5028)\end{array}$ & $\begin{array}{c}\text { A }- \\
(n=1035)\end{array}$ & $\begin{array}{c}\text { A }+ \\
(n=3993)\end{array}$ & $P$-value \\
\hline TT $(\mu \mathrm{g} / \mathrm{l})$ & $4.77(1.79)$ & $4.86(1.60)$ & $4.75(1.84)$ & 0.09 \\
FT $(\mathrm{ng} / \mathrm{l})$ & $81.81(32.07)$ & $83.20(30.75)$ & $81.45(32.40)$ & 0.11 \\
LH $(\mathrm{mUl} / \mathrm{ml})$ & $5.00(3.52)$ & $4.93(3.61)$ & $5.02(3.50)$ & 0.46 \\
FSH $(\mathrm{mUl} / \mathrm{ml})$ & $7.01(6.62)$ & $6.56(5.54)$ & $7.13(6.87)$ & 0.04 \\
\hline
\end{tabular}

$\mathrm{TT}$, total testosterone; FT, free testosterone. difference was observed in the percentage of subjects with low or normal free testosterone who had answered positively to 'any other three questions' of the ADAM questionaire (Table 3).

When calculating the qADAM score, there was a significant difference between hypogonadal men and normal subjects $(4.3 \pm 2.6$ vs $4.1 \pm 2.6 ; P=0.03)$. However, when excluding items 1 and 7 which are related to sexual disorders (modified qADAM score ranging between 0 and 8 ), a statistical difference was no longer observed between the two groups (3.07 \pm 2.2 vs $3.12 \pm 2.2 ; P=0.34$ ).

The ROC curve of the qADAM for the free testosterone cutoff of $70 \mathrm{ng} / \mathrm{l}$ is shown in Fig. 1. The area under the curve was $0.519(P=0.025)$, indicating

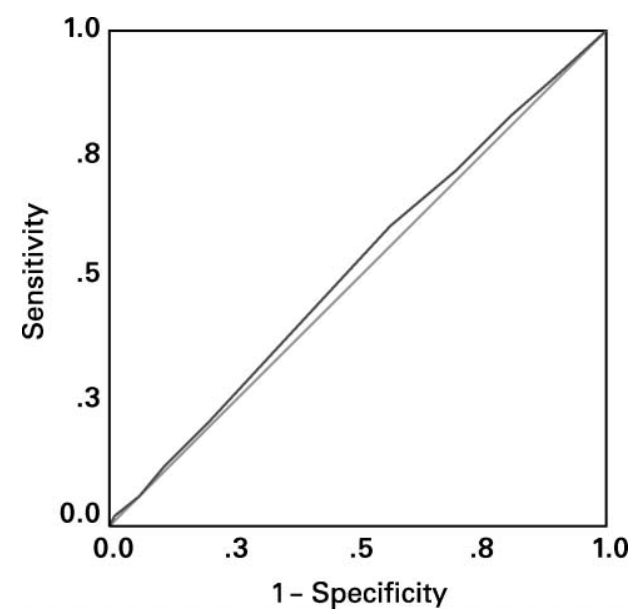

Figure 1 Receiver operating characteristics (ROC) curve of qADAM for free testosterone $<70 \mathrm{ng} / \mathrm{l}$. Diagonal segments are produced by ties. The area under the diagonal represents $50 \%$ of the total area under the maximal ROC curve. 
Table 3 Prevalence (\%) of positive answers for the 10 items of the ADAM questionnaire in the total sample and in men with free testosterone level below or above $70 \mathrm{ng} / \mathrm{l}$.

\begin{tabular}{llcccc}
\hline Item & Question's topic & Total $(n=5028)$ & $<\mathbf{7 0} \mathbf{n g} / \mathbf{l}(n=1939)$ & $\geq \mathbf{7 0} \mathbf{n g} / \mathbf{l}(n=3088)$ & $\boldsymbol{P}$-value $(<70$ vs $\geq 70)$ \\
\hline 1 & Libido & 50.5 & 54.7 & 47.9 & $<0.001$ \\
2 & Energy & 53.3 & 53.9 & 52.9 & 0.49 \\
3 & Strength endurance & 57.7 & 58.6 & 57.1 & 0.30 \\
4 & Height & 15.1 & 17.2 & 13.8 & 0.001 \\
5 & Enjoyment of life & 22.9 & 21.9 & 23.6 & 0.15 \\
6 & Sad/grumpy & 24.4 & 24.5 & 24.4 & 0.01 \\
7 & Erections & 59.4 & 61.6 & 58.0 & 0.96 \\
8 & Playing sport & 49.5 & 49.5 & 49.5 & 0.30 \\
9 & Sleeping after dinner & 50.7 & 49.7 & 51.2 & 0.02 \\
10 & Work performance & 35.2 & 37.2 & 34.0 & $<0.001$ \\
Q1 or Q7 & & 67.6 & 70.9 & 65.5 & 0.43 \\
Any other 3 questions & & 57.6 & 58.3 & & \\
\hline
\end{tabular}

that the quantitative score (qADAM) provides statistically better information than random $(0.5)$, even if this improvement remains highly marginal.

Table 4 summarizes sensitivity, specificity, positive predictive value, negative predictive value and the global efficiency of ADAM for the detection of subjects with low free testosterone levels, based on various cutoffs of serum free testosterone levels.

The global efficiency of the ADAM test, i.e. the percentage of subjects who were appropriately classified as either hypogonadic or normal, based on the results of ADAM, varies between $28.7 \%$ and $59.3 \%$ for free testosterone cutoffs of $50 \mathrm{ng} / \mathrm{l}$ and $90 \mathrm{ng} / \mathrm{l}$ respectively. For the cutoff of $70 \mathrm{ng} / \mathrm{l}$, the global efficiency of ADAM as a screening test for andropause is $44.5 \%$.

\section{Discussion}

The noninvasive ADAM screening test was initially developed in a cohort of Canadian physicians aged 40 years and over (23). The French translation, used in the present study, was tested for the first time in a cohort of Western European (Belgian) males, aged between 50 and 70 years, spontaneously participating in a program assessing their hormonal status (27). We performed the present trial in a larger sample (5028 elderly men) recruited on the same basis. Our

Table 4 Performance of the ADAM questionnaire for various cutoffs of free testosterone.

\begin{tabular}{lccccc}
\hline \multirow{2}{*}{$\begin{array}{l}\text { Validity criteria } \\
\text { of ADAM test }\end{array}$} & \multicolumn{5}{c}{ Free testosterone cutoff point $(\mathrm{ng} / \mathrm{l})$} \\
\cline { 2 - 6 } & 50 & 60 & 70 & 80 & 90 \\
\hline Sensitivity (\%) & 81.4 & 81.3 & $\mathbf{8 1 . 0}$ & 80.4 & 79.8 \\
Specificity (\%) & 20.9 & 21.2 & $\mathbf{2 1 . 6}$ & 21.6 & 21.4 \\
PPV (\%) & 13.2 & 26.0 & $\mathbf{3 9 . 3}$ & 52.7 & 65.3 \\
NPV (\%) & 88.4 & 76.9 & $\mathbf{6 4 . 4}$ & 50.3 & 36.4 \\
Efficiency (\%) & 28.7 & 36.5 & $\mathbf{4 4 . 5}$ & 52.2 & 59.3 \\
\hline
\end{tabular}

PPV, positive predictive value; NPV, negative predictive value. population differs from the sample used in the initial validation of the ADAM test by their degree of education (lay people versus physicians) and by the process of recruitment (volunteers spontaneously testing their gonadal function versus randomly chosen physicians). The mode of selection of our population may explain the relatively high prevalence of hypogonadism (free testosterone $<70 \mathrm{ng} / \mathrm{l} ; 38.6 \%$ ) compared with the figure of $25 \%$ (bioavailable - free and weakly bound to albumin - testosterone $<70 \mathrm{ng} / \mathrm{ml}$ ) reported in the original population (23). The difference in the definition of hypogonadism between the two studies ('free' versus 'bioavailable' testosterone $<70 \mathrm{ng} / \mathrm{l}$ ) may also be a factor in explaining the discrepancies observed in the prevalence of hypogonadism. The objective of the present trial was not to report the exact prevalence of hypogonadism in community-dwelling, elderly men living in our area but to evaluate whether a simple, self-administered questionnaire, the Androgen Deficiency in Aging Males (ADAM) score, could be used as a surrogate to serum free testosterone testing for the identification of androgen deficiency. We also aimed at the assessment of a modified 'quantitative' version of the score (qADAM) and compared its diagnostic value with the results obtained with the original tool (23).

At the cutoff value of $70 \mathrm{ng} / \mathrm{l}$ for free testosterone, the sensitivity and specificity of the ADAM test, in our population, were $81.0 \%$ and $21.6 \%$ respectively. These values are in agreement with the values previously reported in a similar population (sensitivity from $80.14 \%(27)$ to $82.2 \%(29,30)$ and specificity from $32.23 \%(27)$ to $34.8 \%$ (30)). That the free testosterone threshold is associated with optimum sensitivity was previously demonstrated by Legros \& Delhez (27). While the sensitivity is in the same range as reported in the population of Canadian physicians (23) used for the initial validation of the ADAM score (88\%), the specificity obtained in our study is significantly lower than described in that paper $(60 \%)$. This may also reflect the difference in the two populations. In our study, elderly men with symptoms suggestive, but 
not pathognomonic, of hypogonadism may be more prone than healthy people to attend the screening spontaneously. This may lead to the recruitment of a large population for whom symptoms resulting in a positive answer to one or more questions from the ADAM score may be linked to co-morbidities mimicking the clinical expression of hypogonadism. In a previous study (30), performed in a similar population as the one used in the present trial, and also reporting low values for ADAM score specificity, a high prevalence of depressed mood was reported in males with a positive ADAM test and normal free testosterone levels. In this particular trial, the Caroll Rating Scale (CRS) (31), a widely accepted depression scale, was significantly correlated to the ADAM test results $(r=0.66, P<0.05)$. Patients with a positive ADAM test and normal free testosterone levels had a poorer general well-being based on the CRS, the social dysfunction of the General Health (GH-28) instrument and the World Health Organisation Quality of Life questionnaire (WHOQOL), compared with patients with a negative ADAM test and normal free testosterone levels. While we have not specifically assessed the psychological status of our patients, this may be an explanation for the poor specificity of the ADAM test observed in our trial. The absence of significant differences in free or total testosterone levels between $\mathrm{A}+$ and $\mathrm{A}-$ subjects is another expression of the poor specificity of this test in our population.

In our study, the items most frequently associated with low levels of free testosterone were those pertaining to the sexual dimension (libido and strength of erections) and those associated with muscular strength and energy. These items were also associated with the highest prevalence of positive answers in males with low testosterone levels in the initial Canadian publication (23). In both studies, a deficit in the strength of erections is the item most frequently reported by males with low testosterone.

Globally, the overall efficiency of the ADAM score in our population of male volunteers is disappointing, mainly due to its poor specificity. When considering the diagnosis of hypogonadism in males with free testosterone levels below $70 \mathrm{ng} / \mathrm{l}$, the ADAM score has an overall efficiency of $44.5 \%$, reflecting an appropriate classification of males in hypogonadism or not in less than $50 \%$ of the cases. These disappointing results, denying the use of a simple questionnaire as a surrogate to serum free testosterone testing, were also reported with other questionnaires. T'sjoen et al. investigated the relationships between male climacteric symptoms assessed by the Aging Male Symptoms (AMS) questionnaire with circulating androgen levels (32). In a population of 161 healthy, elderly, community-dwelling ambulatory men aged 74-89 years, this 17-item scale, consisting of three dimensions (psychological, somatovegetative and sexual) was not correlated with free testosterone serum levels.
The authors concluded that climacteric symptoms in males assessed with the AMS scale failed to predict androgen levels. This conclusion supports our own results. These consistent results confirm the extreme difficulty of developing a questionnaire based on signs and symptoms as a potential surrogate to biochemical determinations. In a complex syndrome, as andropause is in aging males, hormonal levels and physical or psychological complaints may reflect different but complementary aspects of the problem. This perception raises the issue of the validity of a single measurement of testosterone (absence of information about the individual lifetime hormone profile of a subject) to characterize an individual as andropausal. Due to the complexity of the clinical presentation of the andropausal state, it may be that measurement of clinical symptoms or quality of life is a better way of assessing patients in this particular category. At any rate, screening tests are frequently characterized by high sensitivity and a relatively low specificity, and may be considered as particularly useful in identifying patients who should not be submitted to further investigations. In several disorders, their ability to select patients with a high risk of presenting the disease has been questioned. We and others have previously reported similar findings for a clinical questionnaire as a surrogate to bone densitometry testing in postmenopausal osteoporosis (33).

We also investigated whether a modified quantitative version of the ADAM score (qADAM) would be more effective for the identification of hypogonadal males. Our results do not support this hypothesis. The area under the curve calculated for the qADAM score used for the identification of patients with free testosterone levels below $70 \mathrm{ng} / \mathrm{l}$, while reaching the level of statistical significance, is of extremely poor clinical relevance. The qADAM score does not provide any significant benefit compared with the original tool (23).

In conclusion, our results suggest that the ADAM test has a high sensitivity to identify aging males with low free testosterone levels. However, due to its lack of specificity, mainly observed in the population of males spontaneously consulting for assessment of their gonadal function, this test, in its original version or in a modified quantitative version, cannot be used as a surrogate to serum free testosterone testing for the identification of androgen deficiency in elderly, communitydwelling males.

\section{Acknowledgements}

We gratefully acknowledge Ms Madeleine Conte-Tassin, coordinator of the interdisciplinary Centre for the Andropause for her valuable help. We also thank M Jean-Marie Delheuze, MD, and Ms Jacqueline Trinon. 


\section{References}

1 Ethgen O, Richy F, Gosset C, Hanssens L \& Reginster J-Y. Prévention de la vulnérabilité de la personne âgée: un défi démographique. Revue Médicale de Liège 200358 175-182.

2 Kalache A. Gender-specific health care in the 21st century: a focus on developing countries. The Aging Male 20025 129-138.

3 Lamberts SWJ. The endocrinology of gonadal involution: menopause and andropause. Annales d'Endocrinologie 200364 77-81.

4 Morley JE. Androgens and aging. Maturitas 200138 61-73.

5 Morales A. Heaton JPW \& Carson CC. Andropause: a misnomer for a true clinical entity. Journal of Urology 2000163 705-712.

6 Juul A \& Skakkebaek NE. Androgens and the ageing male. Human Reproduction Update 20028 423-433.

7 Swerdloff RS \& Wang C. Three-year follow-up of androgen treatment in hypogonadal men: preliminary report with testosterone gel. The Aging Male 20036 207-211.

8 Von Eckardstein S \& Nieschlag E. Treatment of male hypogonadism with testosterone undecanoate injected at extended intervals of 12 weeks: a phase II study. Journal of Andrology 200223 419-425.

9 Wang C, Swerdloff RS, Iranmanesh A, Dobs A, Snyder PJ, Cunningham G, Matsumoto AM, Weber T \& Berman N. Transdermal testosterone gel improves sexual function, mood, muscle strength, and body composition parameters in hypogonada men. Testosterone Gel Study Group. Journal of Clinical Endocrinology and Metabolism 200085 2839-2853.

10 Behre HM, Von Eckardstein S, Kliesch S \& Nieschlag E. Long-term substitution therapy of hypogonadal men with transscrotal testosterone over 7-10 years. Clinical Endocrinology $1999 \quad \mathbf{5 0}$ 629-635.

11 Nieschlag E, Buchter D, Von Eckardstein S, Abshagen K, Simoni M \& Behre HM. Repeated intramuscular injections of testosterone undecanoate for substitution therapy in hypogonadal men. Clinical Endocrinology 199951 757-763.

12 Swerdloff RS \& Wang C. Dihydrotestosterone: a rationale for its use as a non-aromatizable androgen replacement therapeutic agent. Baillieres Clinical Endocrinology and Metabolism 199812 501-506.

13 Behre HM, Kliesch S, Leifke E, Link TM \& Nieschlag E. Long-term effect of testosterone therapy on bone mineral density in hypogonadal men. Journal of Clinical Endocrinology and Metabolism 1997 82 2386-2390.

14 Wang C, Eyre DR, Clark R, Kleinberg D, Newman C, Iranmanesh A, Veldhuis J, Dudley RE, Berman N, Davidson T, Barstow TJ, Sinow R, Alexander G \& Swerdloff RS. Sublingual testosterone replacement improves muscle mass and strength, decreases bone resorption, and increases bone formation markers in hypogonadal men: a clinical research center study. Journal of Clinical Endocrinology and Metabolism 199681 3654-3662.

15 Rhoden EL \& Morgentaler A. Risk of testosterone-replacement therapy and recommendations for monitoring. New England Journal of Medicine $20043 \mathbf{3 0} 482-492$.

16 Snyder PJ. Hypogonadism in elderly men - what to do until the evidence comes. New England Journal of Medicine $20043 \mathbf{3 5 0}$ 440-442.

17 Morales A \& Tenover JL. Androgen deficiency in the aging male: when, who, and how to investigate and treat. Urologic Clinics of North America 200229 975-982.

18 Flynn V \& Hellstrom WJG. Androgen deficiency in the aging male: pathophysiology, diagnosis, and treatment alternatives. Current Urology Reports 20012 473-479.
19 Morley JE. Testosterone replacement in older men and women. Journal of Gender Specific Medicine 2001 4 49-53.

20 Nolten WE. Androgen deficiency in the aging male: when to evaluate and when to treat. Current Urology Reports 20001 313-319.

21 Conway K, Heineman LAJ, Giroudet C, Johannes EJ, Myon E, Taieb C \& Raynaud J-P. Harmonized French version of the Aging Males' Symptoms scale. The Aging Male 20036 $106-109$.

22 Heinemann LAJ, Saad F, Zimmermann T, Novak A, Myon E, Badia X, Potthoff P, T'Sjoen G, Pöllanën P, Goncharow NP, Kim S \& Giroudet C. The Aging Males' Symptoms (AMS) scale: update and compilation of international versions. Health and Quality of Life Outcomes 2003115.

23 Morley JE, Charlton E, Patrick P, Kaiser FE, Cadeau P, McCready D \& Perry HM. Validation of a screening questionnaire for androgen deficiency in aging males. Metabolism $2000 \mathbf{4 9}$ 1239-1242.

24 Smith KW, Feldman HA \& McKinlay JB. Construction and field validation of a self-administered screener for testosterone deficiency (hypogonadism) in ageing men. Clinical Endocrinology $200053703-711$.

25 Heinemann LAJ, Zimmermann T, Vermeulen A, Thiel C \& Hummel W. A new aging males symptoms rating scale. The Aging Male 19992 105-114.

26 Vermeulen A, Verdonck L \& Kaufman JM. A critical evaluation of simple methods for the estimation of free testosterone in serum. Journal of Clininical Endocrinology and Metabolism $1999 \mathbf{8 4}$ 3666-3672.

27 Legros J-J \& Delhez M. Détection de la déficience androgénique chez l'homme de plus de 50 ans: utilisation d'une version française du test ADAM. Médecine et Hygiène $2002 \mathbf{6 0}$ $1490-1495$.

28 Vermeulen A. Androgen replacement therapy in the aging male a critical evaluation. Journal of Clinical Endocrinology and Metabolism $2001862380-2387$.

29 Delhez M, Hansenne M \& Legros J-J. Andropause and psychopathology: minor symptoms rather than pathological ones. Psychoneuroendocrinology $2002 \mathbf{2 8} 863-874$.

30 Delhez M, Hansenne M, Luyckx F \& Legros J-J. Oue penser d'un test ADAM positif en l'absence d'hypogonadisme? Annales d'Endocrinologie 200162177.

31 Carroll BJ, Feinberg M, Smouse PE, Rawson SG \& Greden JF. The Carroll rating scale for depression. I. Development, reliability and validation. British Journal of Psychiatry 1981138 194-200.

32 T'Sjoen G, Goemaere S, De Meyere M \& Kaufman JM. Perception of males' aging symptoms, health and well-being in elderly community-dwelling men is not related to circulating androgen levels. Psychoneuroendocrinology 200429 201-214.

33 Richy F, Gourlay M, Ross PD, Sen SS, Radican L, De Ceulaer F, Ben Sedrine W, Ethgen O, Bruyere O \& Reginster J-Y. Validation and comparative evaluation of the osteoporosis self-assessment tool (OST) in a Caucasian population from Belgium. Quarterly Journal of Medicine 200497 39-46.

Received 9 March 2004 Accepted 31 May 2004 